\title{
Trace voltammetric measurements of cancerostatic actinomycin-C1
}

\author{
M.S. Ibrahim ${ }^{1, *, * *}$ and Y.M. Temerk ${ }^{2}$ \\ ${ }^{1}$ Chemistry Department, Faculty of Science, UAE University, P.O. Box 17551, Al-Ain, United Arab Emirates \\ ${ }^{2}$ Chemistry Department, Faculty of Science, Assiut University, Assiut, Egypt
}

\begin{abstract}
Adsorptive accumulation in stripping voltammetry has been applied for trace measurements of the cancerostatic drug actinomycin-C1 (ACT). Accumulation is achieved by controlled adsorption of ACT film on the hanging mercury drop electrode (HMDE). The cathodic stripping response was evaluated with respect to accumulation time, concentration dependence, solution conditions and other variables. The limit of detection after 5 minutes preconcentration is $1 \mu \mathrm{g} \mathrm{L}^{-1}\left(8 \times 10^{-10} \mathrm{M}\right)$. The effects of possible interferences, due to coexisting metal ions or organic substances, are evaluated. The applicability of the method to the determination of ACT in untreated urine is described.
\end{abstract}

Key words. Actinomycin-C1 - stripping voltammetry - hanging mercury drop electrode.

\section{Introduction}

Actinomycin (ACT) was one of the first potent cytotoxic drugs currently used among the antitumoral agent [1]. Due to great pharmacological activity [2-6] a highly sensitive analytical method is essential for the evaluation and administration of this drug. Measurements of low levels of ACT commonly rely on spectroscopy or chromatography [7-10]. Adsorption stripping voltammetry, based on adsorptive accumulation, is a very sensitive technique for the determination of drugs and organic substances of biological significance.
Since the technique is rapid and sensitive, many applications have been studied [11]. Recently the electroanalytical determination of some biological substances using stripping voltammetry was investigated by us [12-16].

The basic d.c polarographic behaviour of ACT at the dropping mercury electrode (DME) was first studied in connection with physicochemical properties by Berg et al. [17-19] who detected strong adsorption at higher concentrations. A detailed examination of the process of ACT adsorption, the oxidation and reduction of adsorbed ACT and layer

\footnotetext{
* Cor respondence and reprints.

** Permanent address: Chemistry Department, Faculty of Science, Assiut University, Assiut 71516, Egypt.

Received December 03, 1997; r evised F ebruary 17, 1998; accepted February 24, 1998.
} 
reorientation has been carried out by us [20] using cyclic voltammetry $(\mathrm{CV})$ and phase sensitive a.c. voltammetry. ACT was found to adsorb very strongly onto HMDE, retaining its characteristic electroactivity in the adsorbed state. This phenomenon can be exploited for the electroanalytical determination of ACT with the aid of adsorption accumulation in stripping voltammetry. In the present work adsorptive accumulation technique is applied for the trace determination of the cancerostatic drug ACT, figure 1.

Various considerations of the experimental variables and the processes which take place on the hanging mercury drop electrode were also taken into account.

\section{Materials and methods}

\section{Instrumentation}

A PAR Model 303 HMDE was used in conjunction with a PAR Model 264A polarographic analyzer/ stripping voltammetry and advanced $X-Y$ recorder Model RE0151 for cathodic adsorptive stripping (CAS) voltammetric measurements. The cell was maintained at $22 \pm 0.5^{\circ} \mathrm{C}$. An $\mathrm{Ag} / \mathrm{AgCl}$ saturated $\mathrm{KCl}$ reference electrode and a Pt wire auxiliary electrode were used. A stir-head bar and a PAR Model 305 stirrer were also used for CAS voltammetry.

\section{Reagents and procedure}

Actinomycin-C1 was a gift from Zimet (BeutenbergInstitute, Jena/ Germany) and was used without further purification. Stock solutions were prepared by dissolving the drug in methyl alcohol. The supporting electrolyte was Britton-Robinson (BR) buffer brought to a constant ionic strength $0.5 \mathrm{KM}$ (or $1.5 \mathrm{KM}, \mathrm{SO}_{4}^{2-}$ ) by the addition of $\mathrm{NaX}$ $\left(X=\mathrm{Cl}^{-}, \mathrm{ClO}_{4}^{-}, \mathrm{NO}_{3}^{-}, \mathrm{SO}_{4}^{2-}\right)$ and adjusted to the desired $\mathrm{pH}$. Twice-distilled water was used to prepare the solutions. The $\mathrm{pH}$ was measured using a Radiometer model M64 digital $\mathrm{pH}$-meter. Human urine samples were used shortly after collection. $5 \mathrm{~mL}$ of the probe solution was added to the cell and purged with oxygen-free nitrogen for $5 \mathrm{~min}$. When preconcentration was done in stirred solutions, a quiescent period of $15 \mathrm{~s}$ was allowed before the potential scan was started.

\section{Results and discussion}

\section{A.c and cyclic voltammetric measurements}

The adsorption behaviour observed for actinomycin at a HMDE has previously been reported [20] using a.c and cyclic voltammetry. In the $\mathrm{pH}$ range $2-11.2$ and at very low bulk concentrations of ACT the a.c voltammograms show a broad and deep pit around the electrocapillary point of zero charge of the pure supporting electrolyte (Fig. 2) (potential of maximum adsorption $E_{\mathrm{m}}=-0.85 \mathrm{~V}$ ). This pit reflects the formation of a compact adsorbed film due to pronounced lateral interaction of the adsorbed species in the potential range from $-0.2 \mathrm{~V}$ to $-1.4 \mathrm{~V}$ [21-26]. Low average surface coverage $S_{\mathrm{m}}\left(0.48 \mathrm{~nm}^{2}\right)$ for an ACT molecule in the compact film indicates a dense packed structure of molecules oriented perpendicularly towards the surface of the electrode. Over the $\mathrm{pH}$ range investigated $(\mathrm{pH} 4.5-9.0)$

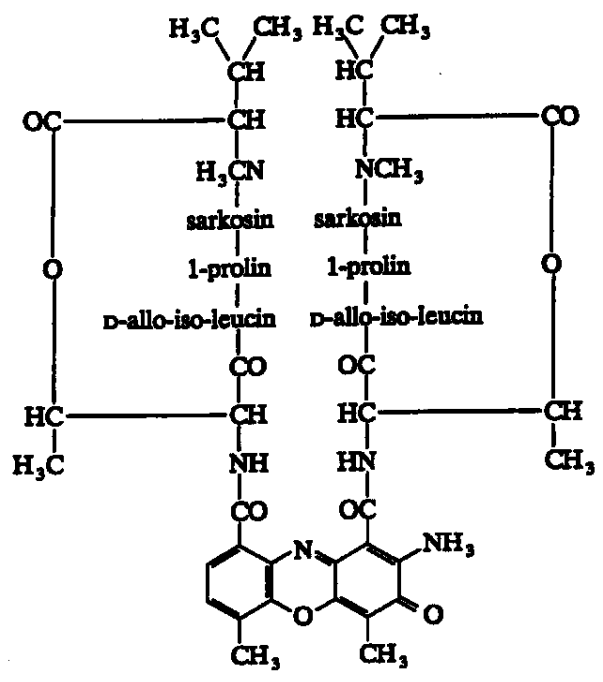

Fig. 1. Actinomycin-C1.

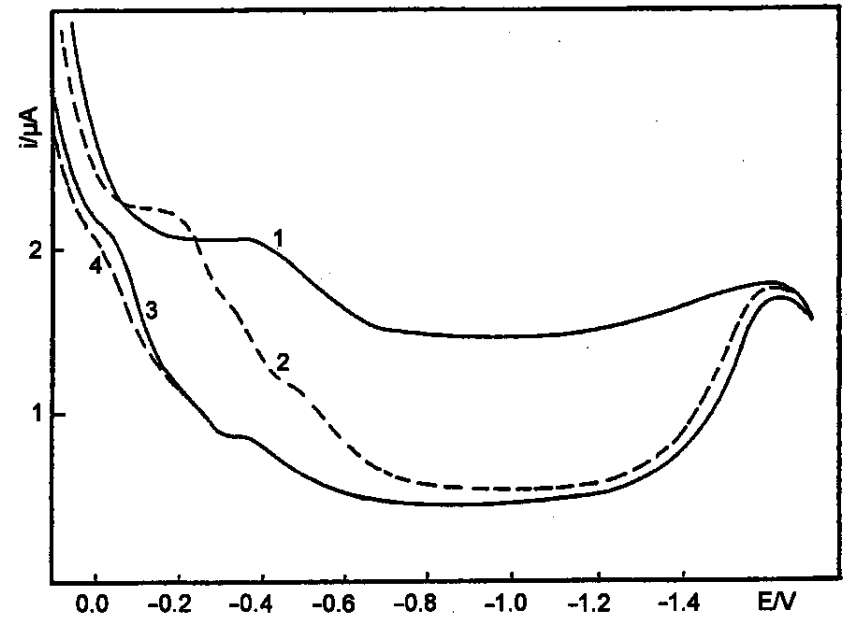

Fig. 2. Out-of-phase a.c voltammetric curves of ACT at the HMDE (pH 7.2), ACT concentrations/ $\mu \mathrm{M}$ : (1)0.0; (2)2.9; (3)4.8, (4)6.6. Scan rate $2 \mathrm{mVs}^{-1}$, amplitude $5 \mathrm{mV}$, Phase angle $90^{\circ}, 5{ }^{\circ} \mathrm{C}$, Frequency $330 \mathrm{~Hz}$ and $t_{\mathrm{a}}=180 \mathrm{~s}$.

the cyclic voltammetric behaviour of ACT shows one cathodic peak and the corresponding oxidation peak. This cathodic peak reflects the reduction of the protonated phenoxazone moiety in the adsorbed state with an irreversible uptake of two electrons per molecule [18].

The previous results of a.c and cyclic voltammetry indicate the adsorption and association of ACT and the effective interfacial accumulation of the ACT film on the electrode surface. Controlled adsorption accumulation of ACT at the HMDE provides the basis for the direct stripping measurements of ACT in the nmol concentration range. The results of the characterization, optimization and applications of a highly sensitive method for trace determination of ACT by adsorptive stripping voltammetry are presented in the following sections. 


\section{Influence of $\mathrm{pH}$ and preconcentration time}

The CAS current of ACT was recorded as a function of potential in BR buffer solutions containing $25 \%$ methanol of varying $\mathrm{pH}(2.2-10.2)$ (Fig. 3). The CAS peaks are to be attributed to the reduction of the phenoxazone moiety of the adsorbed ACT film at the electrode surface. The CAS peak is $\mathrm{pH}$ dependent in that shifts to more negative potentials with increasing of $\mathrm{pH}$. At $\mathrm{pH} 7.2$ the reduction response gave a concentration sensitive peak height compared to media with other $\mathrm{pH}$ 's. At $\mathrm{pH}>8.2$ the reduction response decreases because the protonation kinetics contribute progressively to the control of the overall rate of the ACT reduction. Therefore the optimum $\mathrm{pH}$ value for further CAS studies of ACT was 7.2.

A necessary prerequisite for the application of cathodic adsorptive stripping voltammetry is that the adsorption equilibrium is attained at the HMDE before the reduction response is measured. The effect of adsorption time $\left(t_{\mathrm{a}}\right)$ on CAS voltammograms is followed over a wide concentration range of the investigated compound. The stripping peak height of the adsorbed ACT film increases with the adsorption time in the form of an adsorption isotherm (Fig. 4). As in all types of stripping measurements, the choice of accumulation time requires a tread-off between sensitivity and speed. At concentration levels less than $10^{-7} \mathrm{~mol} / \mathrm{L}$, the constancy of the peak height is recorded after ca. 5 min. A pre-electrolysis time of $5 \mathrm{~min}$ was adopted for the stripping analysis of ACT.

\section{Effect of the anions of the supporting electrolyte}

The effect of replacing the $\mathrm{Cl}^{-}$anion in $\mathrm{BR}$ buffer by various anions such as $\mathrm{NO}_{3}^{-}, \mathrm{SO}_{4}^{2-}$ and $\mathrm{ClO}_{4}^{-}$was investigated. The results indicate that the cathodic reduction peak decreases in the order $\mathrm{NO}_{3}^{-}>\mathrm{ClO}_{4}^{-}>\mathrm{SO}_{4}^{2-}>\mathrm{Cl}^{-}$. The main difference is connected with structural changes in the electrical double layer due to the specific adsorption of the anions of the sup- porting electrolyte. In this case the electrostatically attracted ions of the solvent repel the adsorbed molecules from the electrode surface and decrease the forces of non-electrostatic adsorption of ACT molecules at a charged interface. The aforementioned results indicate that replacing halide anions $\left(\mathrm{Cl}^{-}\right)$by oxyanions $\left(\mathrm{NO}_{3}^{-}\right.$or $\mathrm{ClO}_{4}^{-}$or $\left.\mathrm{SO}_{4}^{2-}\right)$ increases the effective adsorption of ACT at charged electrode. This indicates that halide anions are present as an interface and their specific adsorption hinders the formation of a condensed film of ACT and disturbs the stacking interaction of adsorbed molecules. On the other hand the results show that $\mathrm{NO}_{3}^{-}$exhibits the smallest tendency for specific adsorption anion and less electrostatic forces on the positively charged mercury surface. This reflects the rule of anions of indifferent supporting electrolyte on the degree of adsorption and accumulation of ACT film at the charged interface [26].

\section{Effect of adsorption potential, scan rate and pulse amplitude}

The amount of the ACT accumulated on the electrode surface, is also affected by other variables such as accumulation potential, scan rate and pulse amplitude in addition to the variables of solution, concentration and adsorption time. The effect of the adsorption potential $\left(E_{\mathrm{a}}\right)$ was followed at pH 7.2 between $+0.1 \mathrm{~V}$ and $-0.25 \mathrm{~V}$ for ACT. The peak height decreased markedly with shifting the potential to more negative values than $-0.1 \mathrm{~V}$ and no measurable peak was seen at $E_{\mathrm{a}}=-0.25 \mathrm{~V}$. The optimum accumulation potential was found to be $0.0 \mathrm{~V}$. The dependence of the reduction peak on scan rate shows that a scan rate of $20 \mathrm{mV} / \mathrm{s}$ gave a maximum response compared to that of $10 \mathrm{mV} / \mathrm{s}$ or $5 \mathrm{mV} / \mathrm{s}$. However, at scan rates higher than $20 \mathrm{mV} / \mathrm{s}$ the width of the peak increases markedly and its height decreases. Therefore, a scan rate of $20 \mathrm{mV} / \mathrm{s}$ was chosen for the stripping analysis experiments. CAS voltammograms of ACT recorded at various pulse amplitude (Fig. 4) illustrate how the peak height increases as the pulse ampli-

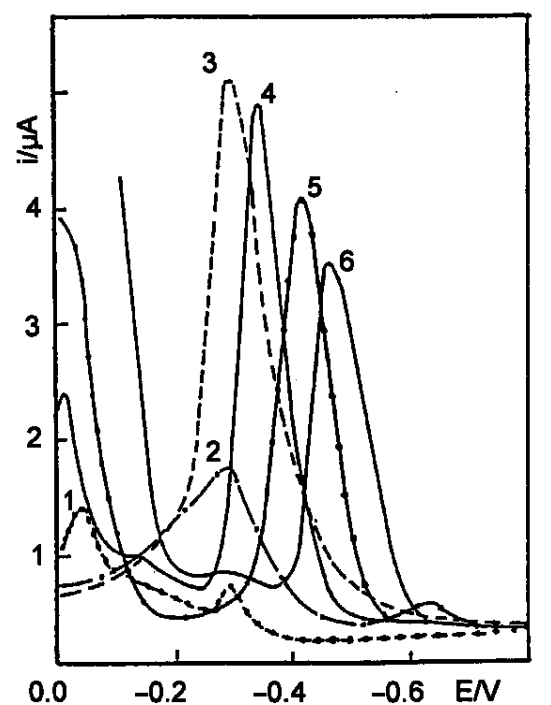

Fig. 3. Effect of $\mathrm{pH}$ on the CAS peak of $1 \mu \mathrm{M}$ of ACT. Scan rate $20 \mathrm{mVs}^{-1}, t_{\mathrm{a}}=30 \mathrm{~s}, E_{\mathrm{a}}=0.0 \mathrm{~V}$ and pulse amplitude $100 \mathrm{mV}$. $\mathrm{pH}(1) 2.2$; (2)5.2; (3)7.2; (4)8.2; (5)9.2 and (6)10.2.

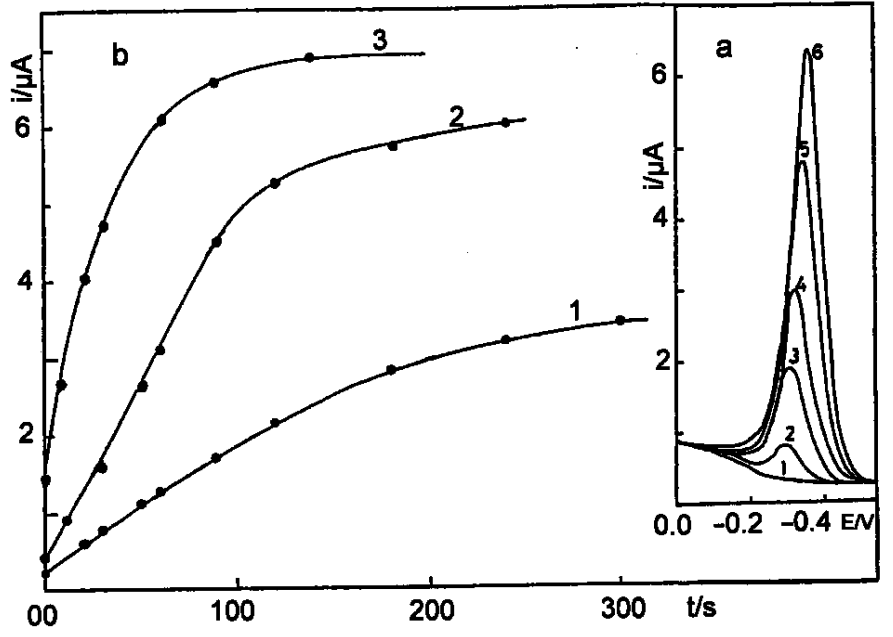

Fig. 4. (a) CAS voltammograms for $0.4 \mu \mathrm{M}$ ACT following 0.0(1); 10(2); 50(3); 60(4);120(5) and 240(6) sec preconcentration (pH 7.2). Other conditions as in figure 3. (b) Peak height dependence of the CAS peak on the adsorption time at various ACT concentration: (1) 0.2 ; (2) 0.4 and (3) $1 \mu \mathrm{M}$. 
tude is increased. Adsorptive accumulation in stripping voltammetry of ACT was performed at $100 \mathrm{mVpp}$ pulse amplitude.

\section{Quantitative trace determination of actinomycin}

The above mentioned results show that the optimum conditions for adsorption accumulation in stripping voltammetry of ACT were the following: $\mathrm{pH} 7.2$ (in presence of $\mathrm{NO}_{3}^{-}$), $100 \mathrm{mVpp}$ pulse amplitude, $20 \mathrm{mV} / \mathrm{s}$ scan rate, 5 minutes accumulation time and $0.0 \mathrm{~V}$ adsorption potential. The variation of CAS peak height with concentration of ACT is represented by the straight line equation $i p=a C+b$ where $a$ and $b$ are slope and the intercept of straight line respectively. The data for three to five replicated measurements were subject to a least square refinement. The calibration curve generated over the concentration range $1.0 \times 10^{-9}$ to $2.0 \times$ $10^{-7} \mathrm{~mol} \mathrm{~L}^{-1}$ had a slope of $(10.5 \pm 0.8) \times 10^{9} \mathrm{nA} / \mathrm{mol} \mathrm{L}^{-1}$ and an intercept of $50 \pm 10 \mathrm{nA}$; the regression coefficient of the fit was 0.998 . The relative standard deviations for ten determinations of $4 \times 10^{-8} \mathrm{~mol} \mathrm{~L}^{-1}$ and $4 \times 10^{-9} \mathrm{~mol} \mathrm{~L}^{-1} \mathrm{ACT}$ were $1.74 \%$ and $1.85 \%$, respectively. The limits of detection were calculated from $3 \times$ the noise of the determination of a low level of ACT. A detection limit of $8.0 \times 10^{-10} \mathrm{~mol} \mathrm{~L}^{-1}$ was estimated from quantitation of ACT under the optimum conditions. This indicates that the application of CAS mode for trace determination of ACT is extremely sensitive.

\section{Interference study}

Interferences for coexisting metal ions capable of forming complexes with ACT or depositing at the mercury electrode were evaluated. Metal ions tested at the $8 \times 10^{-5} \mathrm{M}$ level and found not to interfere in the determination of $1.0 \times 10^{-7} \mathrm{M}$ ACT were $\mathrm{Pb}(\mathrm{II}), \mathrm{Cd}(\mathrm{II}), \mathrm{Cu}(\mathrm{II}), \mathrm{Al}(\mathrm{III}), \mathrm{Fe}(\mathrm{III}), \mathrm{Cr}(\mathrm{III})$, $\mathrm{Ni}(\mathrm{II}), \mathrm{Co}(\mathrm{II})$ and $\mathrm{Zn}(\mathrm{II})$.

However in the presence of $2 \times 10^{-4} \mathrm{M} \mathrm{Zn}$ (II), $\mathrm{Pb}$ (II), $\mathrm{Cd}(\mathrm{II})$ or $\mathrm{Co}(\mathrm{II})$ the peak height of ACT reduced by $45 \%$, $15 \%, 41 \%$ and $23 \%$, respectively. This is probably due to formation of ACT-metal ions complexes in the solution. The competitive adsorption of these complexes decrease the ACT response. Other organic molecules could interfere with the determination of ACT if they adsorb on the mercury drop electrode or if they are electroactive with a reduction potential close to that of ACT compound. Several amino acids were added to the investigated compound to test their possible interference in the optimum conditions. No changes were obtained with $1.0 \times 10^{-4} \mathrm{M}$ glycine, alanine and phenylalanine. No interference was produced by the sugar ribose and galactose. However the addition of $1.7 \times 10^{-4} \mathrm{M}$ oxalic acid or ascorbic acid caused the ACT peak height to diminish by $20 \%$ and $63 \%$, respectively. Triton X-100 was added to the solution as a model surfactant: the sensitivity for ACT was diminished by $43 \%$ in presence of $1.0 \mathrm{mg} \mathrm{L}^{-}$ ${ }^{1}$ Triton and the ACT peak disappeared altogether when 2.5 $\mathrm{mg} \mathrm{L}^{-1}$ Triton was added. Interference as a result of diminished sensitivity caused by the presence of surface active material or by the adsorption of other organic compound, can be overcome to some extent by means of standard addition of the investigated compound.

\section{Actinomycin determination in urine}

Applications of electroanalytical methods directly on analytes present in physiological matrices such as urine or blood serum without any preliminary treatment are more interesting. The determination of ACT in urine was chosen as a practical example. Adsorption stripping voltammogram of a diluted urine sample (9:1 buffer/urine mixture), to which no ACT had been added, is shown in figure 5 (curve marked as 0 ). The influence of the concentration of ACT added to urine was studied over the range $5 \times 10^{-8}$ to $5 \times 10^{-5} \mathrm{M}$. It was found that at $-300 \mathrm{mV}$, ACT displayed a concentration-sensitive peak height, contrary to the case at other potential values. A linear relationship between the peak current and the concentration of ACT in urine was obtained

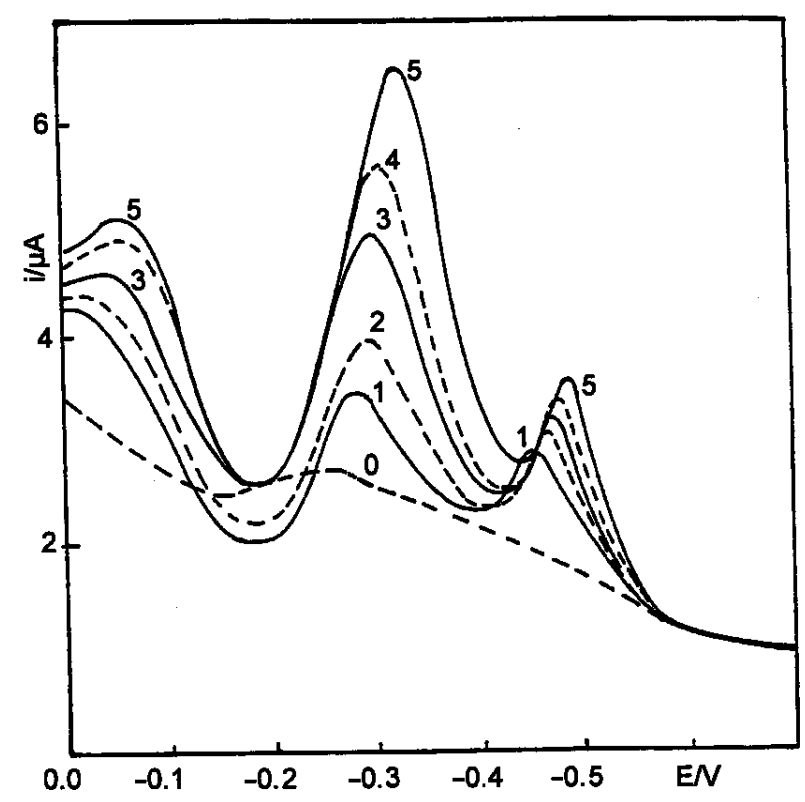

Fig. 5. Concentration dependence of the CAS peak of ACT in 9:1 pH 7.2 buffer/urine mixture. (0) background: (1)3.1 ; (2)4.7 ; (3)13; (4) 20 and (5) $35 \mu \mathrm{M} \mathrm{ACT}$. Other conditions as in figure 3 .

Table 1. Characteristics of the calibration graphs obtained for ACT in urine samples (9:1 buffer/urine mixture) by CAS voltammetry at HMDE (30 s accumulation time).

\begin{tabular}{|c|c|c|c|c|c|}
\hline$P H$ & $\begin{array}{l}\text { Supporting } \\
\text { electrolyte }\end{array}$ & $\begin{array}{c}\text { Range of linearity } \\
\left(\mathrm{mol} L^{-1}\right)\end{array}$ & $r$ & $\begin{array}{c}\text { Slope } \\
\left(n A / m o l ~ L^{-1}\right)\end{array}$ & $\begin{array}{l}\text { Intercept } \\
\quad(n A)\end{array}$ \\
\hline 7.2 & Acetate media ${ }^{a}$ & $9 \times 10^{-8}-5.0 \times 10^{-6}$ & 0.999 & $(2.5 \pm 0.5) \times 10^{8}$ & $98 \pm 10$ \\
\hline 7.7 & Borate buffer & $4 \times 10^{-7}-1.0 \times 10^{-5}$ & 0.999 & $(1.7 \pm 0.6) \times 10^{8}$ & $42 \pm 8$ \\
\hline 7.2 & BR buffer & $4 \times 10^{-7}-2.5 \times 10^{-5}$ & 0.999 & $(1.0 \pm 0.4) \times 10^{8}$ & $148 \pm 15$ \\
\hline
\end{tabular}

a Acetate media consisted of $0.03 \mathrm{M}$ acetic acid and $0.2 \mathrm{M}$ sodium hydroxide. 
(Tab. I). A levelling-off was observed at higher concentrations, indicating saturation of the electrode surface. Detection limit of $1.0 \times 10^{-8} \mathrm{M}$ ACT was calculated based on a signal-to-noise ratio of 3 (3-min. preconcentration time). A clear decrease in the slope of the calibration graph is observed, when comparing with those obtained for the same concentration ranges with ACT standard solutions, which indicates the existence of a matrix effect. The effect of buffer constituents on the adsorptive stripping response of ACT in urine was also investigated (Tab. I). The slope of the straight line calibration curve in the presence of acetate media is higher than the corresponding value in the presence of borate or BR buffer. This may be explained by the reaction of boric acid in BR or in borate buffer with hydroxyl group produced from the reduction of the ketonic group of phenoxazone moiety [13], (Fig. 1). This confirms that the method of determination is more sensitive in the presence of acetate buffer.

\section{Conclusion}

The adsorption preconcentration approach described in this work clearly possesses direct potential for applications involving the routine determination of ACT and related species in both the clinical and the research laboratory. Further optimization of this analysis method for actinomycin-derived compounds and its more intensive application in the characterization of clinical samples is continuing in our laboratory.

\section{References}

1. Grafe, U. Biochemie der Antibiotika, Spektrum Akademie, Heidelberg, 1992.

2. Crooke, S. T.; Duvemay, W. H.; Galven, L.; Prestavko, A. Mol. Pharmacol. 1973, 14, 290.

3. Duvemay, V. H.; Pachter, J. A.; Crooke, T. S. Biochemistry 1979, 18, 4024.
4. Durate-Karim, M.; Ruysschaert, Y. M.; Hildebrand, J. Biochem. Biophys. Res. Commun. 1976, 71, 658.

5. Bianchi, C. A.; Bagnato, A.; Paggi, M. G.; Floridi, A. Exp. Mol. Pathol. 1987, 40, 123.

6. Goodman, L. S.; Gilman, A. "The Pharmacological Basis of Therapeutics" $5^{\text {th }}$ ed. Copyright, 1975; p 1287.

7. Kachani, Z. F. C. Z. Analyt. Chem. 1965, 213, 427.

8. Rzeszotarski, W. J.; Mauger, A. B. J. Chromato gr. 1973, 86, 246.

9. Mauger, A. B.; Stuart, O. A. J. Antibiot. 1990, 43, 220.

10. Cho, S.; Goo, Y. M.; Kim, K. J. Arch. Pharm. Res. 1994, 17, 424.

11. Brainina, K.; Neyman, E. Electroanalytical stripping Methods, Wiley, New-York, 1993.

12. Ibrahim, M. S.; Ahmed, M. E.; Kawde, A. M.; Temerk, Y. M. Analusis 1996, 24, 6.

13. Ibrahim, M. S.; Ahmed, M. E.; Temerk, Y. M.; Kawde, A. M. Anal. Chim. Acta 1996, 328, 47.

14. Ibrahim, M. S.; Temerk, Y. M.; Ahmed, M. E.; Kawde, A. M. Analusis 1996, 24, 84.

15. Ahmed, Z. A.; Ahmed, M. E.; Ibrahim, M. S.; Kamal, M. M.; Temerk, Y. M. Analusis 1994, 22, 82.

16. Ahmed, Z. A.; Ahmed, M. E.; Ibrahim, M. S.; Kamal, M. M.; Temerk, Y. M. Talanta 1994, 41, 659.

17. Frizsche, H.; Lober, G.; Berg, H. Z. Phys. Chem. 1961, 218, 291.

18. Fedoronko, M.; Berg, H. Z. Phys. Chem. 1962, 220, 120.

19. Berg, H. J. Electroanal. Chem. 1965, 10, 371.

20. Ibrahim, M. S.; Ahmed, Z. A.; Temerk, Y. M.; Berg, H. Bioelectrochem. Bioenerg. 1995, 36, 149.

21. Vetterl, V. Collect. Czech. Chem. Commun. 1966, 31, 2105.

22. Vetterl, V. J. Electroanal. Chem. 1968, 19, 169.

23. Krznaric, D.; Valenta, P.; Numberg, H. W. J. Electroanal. Chem. 1975, 65, 863.

24. Baric, V.; Christiah, S. D.; Dryhurst, G. J. Electroanal. Chem. 1979, 85, 355.

25. Jursa, J.; Vetterl, V. Bioelectrochem. Bioenerg. 1984, 12, 137.

26. Temerk, Y. M.; Kamal, M. M.; Ahmed, Z. A.; Ibrahim, M. S. J. Electroanal. Chem. 1989, 260, 201. 